\title{
Tingkat Substitusi Teknikal Marjinal dalam Kombinasi Penggunaan Pupuk pada Usahatani Cabai Merah Besar di Desa Baturiti Kabupaten Tabanan
}

\author{
WAYAN WIDYANTARA \\ Program Studi Agribisnis Fakultas Pertanian Universitas Udayana \\ Jalan PB Sudirman Denpasar 80232 \\ Email : widyantara@unud.ac.id
}

\begin{abstract}
Marginal Rate of Technical Susbtitution in Combined Use of Fertilizer in Large Red Chili Farming in Baturiti Village Tabanan Regency
\end{abstract}

Large red chilli farming is intensive farming, so farmers in managing their farming experience various problems, both problems in farming and environmental issues. The purpose of this study was to determine: (1) marginal rate of technical substitution (MRTS) from a combination of the type of fertilizers used, (2) the effect of changes of the use of fertilizers on the use of other fertilizers, and (3) the optimization of allocation combinations of fertilizers in big red chili farming, whether it had qualified for optimal requirements. The results showed that, from a combination of fertilizers (urea, ZA, KCl, TSP, NPK) used by large red chili farmers, only NPK fertilizer which wassubstitutable with ZA fertilizers and urea fertilizers while other fertilizers are complementary in nature, MRTS of urea with NPKof 0.058 , and MTRS ZA with NPK of 0.118. NPK fertilizers were not perfect substitutes of the ZA and the urea fertilizers. The substitution abilitywas only $11 \%$ against ZA and $13 \%$ against urea. From the combination of the use of fertilizers in large red chillifarming, none of the combinations was optimal. It is suggested farmers should improve their skills in the use of a combination of various types of fertilizers in chillifarming, so that costs can be minimized andthe profit of farming can be maximized.

Keywords: combination of fertilizer allocation, optimization of the use of fertilizers, large red chilli farming

\section{Pendahuluan}

\subsection{Latar Belakang}

Bali yang merupakan daerah pariwisata, rumah makan, dan restoran berkembang sangat pesat yang mengakibatkan permintaan akan cabai sebagai salah satu bahan bumbu sangat perlu mendapat perhatian. Komoditi cabai merupakan komoditi yang mempunyai nilai ekonomis tinggi, dan harganya sering kali mengalami fluktuasi sepanjang tahun karena terbatasnya persediaan. 
Pada sisi petani produsen, sebahagian besar petani menguasai lahan yang relative sempit, keterampilan dalam mengelola sarana produksi menjadi hal yang tidak boleh diremehkan dalam usaha memperoleh produksi tinggi dan stabil. Usahatani cabai merah besar merupakan usahatani yang intensif, sehingga dalam mengelola usahataninya, petani cabai merah besar mengalami berbagai masalah, baik masalah dalam usahatani ataupun masalah lingkungan usahataninya, seperti : terbatasnya permodalan, keterampilan dalam mengkombonasikan pupuk, keterampilan pembuatan benih, penyesuaian dengan iklim, pengalaman petani, mengendalikan serangan hamapenyakit (OPT), serta masalah harga jual.

Dengan asumsi bahwa petani cabai merah besar berusahatani dengan tujuan memperoleh laba usahatani yang maksimum, maka dengan luas garapan yang sempit praktek sehari hari petani adalah cenderung mengejar efisiensi teknis, yang tergambar dari upaya memaksimalkan produksi. Keberhasilan usahatani ditentukan oleh resultan dari berkerjanya faktor faktor produksi yang sangat banyak, baik yang bisa dikendalikan maupun yang tidak bisa dikendalikan. Faktor lingkungan yang tidak dapat dikendlikan merupakan factor given. Sedangkan faktor yang dapat dikendalikan sebenarnya ada dua, yaitu : pemilihan benih/bibit dan pengkombinasian pupuk. Pengkombinasian penggunaan pupuk tergantung kepada pengalaman petani dalam berusahatani cabai merah besar. Dalam kerangka memperoleh produktivitas maksimum, apakah petani cabai merah besar telah melakukan kombinasi pupuk dengan baik, bagaimana pengkombinasian pupuk yang dilakukan oleh petani cabai merah besar.

\subsection{Tujuan Penelitian}

Adapun tujuan penelitian ini adalah ingin mengetahui :

1. Tingkat substitusi teknikal marjinal (MRTS) dari kombinasi jenis pupuk yang digunakan oleh petani cabai merah besar.

2. Pengaruh perubahan penggunaan jenis pupuk terhadap perubahan penggunaan pupuk lainnya.

3. Optimasi pengalokasikan kombinasi pupuk dalam usahatani cabai merah besar, apakah telah memenuhi syarat optimal.

\section{Metode Penelitian}

\subsection{Lokasi dan Waktu Penelitian}

Lokasi penelitian ini berada di Desa Baturiti Kabupaten Tabanan Provinsi Bali. Di Kabupaten Tabanan, Desa Baturiti merupakan salah satu sentra penghasil cabai merah besar yang relatif kontinyu sepanjang tahun. Penelitian ini dilaksanakan pada bulan April 2016. 


\subsection{Data dan Metode Pengumpulan Data}

Data yang dipakai dalam penelitian ini adalah data primer dari petani responden dengan menggunakan daftar pertanyaan yang telah disiapkan sebelumnya. Jumlah petani responden sebanyak 56 orang yang diambil secara acak.

\subsection{Variabel Penelitian}

Jenis data yang diambil dari petani meliputi data : luas garapan, jenis pupuk yang digunakan dalam berusahatani cabai, jumlah bibit, festisida, produksi cabai, harga jual cabai, harga benih, harga obat obatan, dan harga beli masing-masing pupuk yang dipakai dalam satu kali periode tanam.

\subsection{Analisis Data}

Data yang telah terkumpul dan tertabulasi analisisnya dimulai dengan fungsi produksi yang menggunakan berbagai jenis pupuk, dengan persamaan regresi:

$$
\mathrm{Q}=\mathrm{ao}+\mathrm{a} 1 \mathrm{Y}+\mathrm{a} 2 \mathrm{X}+\mathrm{a} 3 \mathrm{Z}+\ldots
$$

Dimana $\mathrm{Q}$ adalah produksi (kg/ha), X,Y, Z adalah jenis pupuk (kg/ha) yang digunakan.

$$
\text { MPy }=\mathrm{a} 1 ; \operatorname{MPx}=\mathrm{a} 2 \text { dan } \mathrm{MPz}=\mathrm{a} 3 .
$$

dengan demikian MRTSxy =-a2/a1 ; MRTSzy = - a3/a1 dan MRTSzx = - a3/a2. Semakin MRTSnya berarti semakin sulit terjadi substitusi antara input, sebaliknya semakin besar MRTSnya berarti semakin mudah terjadi substitusi atau tingkat substitusinya semakin tinggi.

Elastisitas substitusi antar input (ES) :

$$
\mathrm{ESxy}=\mathrm{a} 1 . \mathrm{X} / \mathrm{Y} ; \mathrm{ESzy}=\mathrm{a} 2 . \mathrm{Z} / \mathrm{Y} \text { dan } \mathrm{ESxz}=\mathrm{a} 3 . \mathrm{Z} / \mathrm{X}
$$

Jika $\mathrm{ES}=1$ berarti input yang digunakan bersubstitusi penuh, sedangkan jika ES tidak sama dengan 1 berarti input input bersubstitusi sebahagian.

Hubungan biaya dengan jenis pupuk yang digunakan, dipakai persamaan :

$$
\mathrm{C}=\mathrm{py} \mathrm{Y}+\mathrm{pxX}+\text { pzZ dimana } \mathrm{C} \text { jumlah biaya pupuk yang }
$$

digunakan, py, px, pz adalah harga masing masing pupuk ( $\mathrm{Rp} / \mathrm{kg})$. Hubungan antar pupuk yang digunakan akan menjadi persamaan:

$$
\begin{aligned}
\text { py } Y & =\mathrm{C}-\mathrm{px} \mathrm{X}-\mathrm{pzZ} \\
\mathrm{Y} & =\mathrm{C} / \mathrm{py}-\mathrm{px} / \mathrm{pyX}-\mathrm{pz} / \mathrm{pyZ}
\end{aligned}
$$

Slope isobiaya $\Delta \mathrm{Y} / \Delta \mathrm{X}=-\mathrm{px} / \mathrm{py} ; \Delta \mathrm{Y} / \Delta \mathrm{Z}=-\mathrm{pz} / \mathrm{py}$.

Persyaratan optimasi terpenuhi jika MRTS $=$ px/py atau sama dengan pz/py. Jika tidak sama maka optimasi tidak terjadi. Artinya petani produsen belum atau tidak mencapai optimalisasi dalam kombinasi pemakaian pupuk.

\section{Kerangka Teoritis}

Dalam teori ekonomi dijelaskan bahwa, dalam menghasilkan siatu barang atau produk di perlukan factor produksi yang biasa disebut masukan (input). Secara garis besar ada empat factor produksi yaitu : tanah atau lahan, tenaga kerja, modal, dan manajemen. Khususnya dalam agribisnis, pada sub tanaman pangan, faktor 
produksi itu terdirr dari : lahan, pupuk (baik pupuk kimia maupun organik), bibit, festisida, air, tenaga kerja, dan energy. Faktor produksi ini dikelola sedemikian rupa oleh petani-produsen untuk menghasilkan biji, buah, sayur, bunga, serat, kayu, umbi, dan lainnya.

Secara matematis, hubungan produksi dengan input dirumuskan dalam bentuk fungsi produksi.

$$
\begin{aligned}
& \mathrm{Q}=\square(\mathrm{Xi}) \\
& \mathrm{Q}=\square(\mathrm{X} 1, \mathrm{X} 2, \mathrm{X} 3, \mathrm{Xn})
\end{aligned}
$$

$\mathrm{Q}$ adalah produksi, $\square$ adalah fungsi, dan Xi adalah berbagai macam input (X1 $\mathrm{Xn}$ ), misalnya : lahan, bibit, pupuk dan lain lain.

Petani produsen dalam menghasilkan suatu komoditi tidak hanya menggunakan satu macam input (masukan), tetapi menggunakan lebih dari satu input atau beberapa input yang dikombinasikan. Kombinasi dari berbagai macam input agar menghasilkan produk maksimum yang jumlahnya tetap dalam berbagai kombinasi. Produk yang jumlah tetap, dihasilkan oleh berbagai macam kombinasi input secara teoritis disebut Isoquant. Kombinasi input $\mathrm{X}$ dan $\mathrm{Y}$ yang menghasilkan produksi tetap.

$$
\mathrm{Q}=\square(\mathrm{X} \text { dan } \mathrm{Y})
$$

MPx (produk marjinal dari $\mathrm{X})=\Delta \mathrm{Q} / \Delta \mathrm{X}$ dan MPy (produk marjinal $\mathrm{Y})=\Delta \mathrm{Q} / \Delta \mathrm{Y}$. Dengan kombinasi input $\mathrm{X}$ dan $\mathrm{Y}$ yang bersubstitusi dengan menghasilkan produk tetap, maka

$$
\begin{aligned}
& \Delta \mathrm{Y} \cdot \mathrm{MPy}=-\Delta \mathrm{X} \cdot \mathrm{MPx} \\
& \Delta \mathrm{Yq} / \Delta \mathrm{Xq}=-\mathrm{MPx} / \mathrm{MPy}
\end{aligned}
$$

Sehingga slope isoquantnya adalah $\Delta \mathrm{Y} / \Delta \mathrm{X}=-\mathrm{MPx} / \mathrm{MPy}$

Hubungan antara input yang digunakannya, apakah bersifat substitusi ataupun komplementer, dapat dirumuskan dalam persamaan matematik.

$$
\mathrm{Y}=\mathrm{Ao}+\mathrm{A} 1 \mathrm{X}+\mathrm{A} 2 \mathrm{Z}
$$

$\mathrm{X}, \mathrm{Y}, \mathrm{Z}$ adalah input factor yang dikombinasikan untuk menghasilkan $\mathrm{Q}$, sehingga MRTS (marginal rate of technical substitution)nya.

$$
\begin{aligned}
& \text { MRTSxy }=\Delta Y / \Delta X=A 1 \\
& \text { MRTSzy }=\Delta Y / \Delta Z=A 2 \\
& \text { MRTSxz }=-A 2 / A 1 \ldots \ldots
\end{aligned}
$$

A1 menunjukkan kemampuan input $\mathrm{X}$ menggantikan input $\mathrm{Y}, \mathrm{A} 2$ dalah kemampuan input $\mathrm{Z}$ menggantikan input $\mathrm{Y}$, demikian seterusnya. Makin besar nilai A1 berarti makin mudah input $\mathrm{X}$ bersubstitusi dengan input $\mathrm{Y}$, sebaliknya semakin kecil nilai A1 berarti semakin sulit $Y$ digantikan oleh X. Jadi semakin kecil nilai A1 dan A2 berarti semakin sulit kedua faktor itu bersubstitusi atau saling menggantikan. Hubunngan kedua faktor itu secara relative dapat diukur dengan elastisitas substitusi (Es), seberapa jauh factor input $\mathrm{X}$ ditambahkan atau dikurangkan mempengaruhi alokasi factor input $\mathrm{Y}$.

$$
\begin{aligned}
\text { Esxy } & =\Delta Y / \Delta X . X / Y \\
& =\text { MRTS . X/Y } \ldots
\end{aligned}
$$


Pengkombinasian input $(\mathrm{X}, \mathrm{Y})$ dengan porsi porsi tertentu menghasilkan output dengan biaya yang minimum, akan memenuhi persyaratan (Arsyad, 1996).

$$
\begin{array}{ll} 
& \mathrm{MPx} / \mathrm{Px}=\mathrm{MPy} / \mathrm{Py} \ldots \ldots \ldots \\
\text { atau } & \mathrm{Px} / \mathrm{MPx}=\mathrm{Py} / \mathrm{MPy}=\mathrm{MCq}
\end{array}
$$

karena MC harus sama dengan MR, maka :

$$
\mathrm{Px} / \mathrm{MPx}=\mathrm{MRq} \text { dan } \quad \mathrm{Py} / \mathrm{MPy}=\mathrm{MRq}
$$

Kemudian persamaan ini bisa diubah menjadi :

$$
\begin{array}{ccc}
\text { Px }=\text { MPx . MRq menjadi } P x=M R P \\
\text { dan } & \text { Py }=\text { MPy. MRq menjadi Py }=\text { MRP }
\end{array}
$$

MRP adalah marginal revenue of product (penerimaan marjinal produk). Demikian juga Salvatore ( 2002) mengatakan bahwa untuk memaksimumkan laba, suatu perusahaan sebaiknya menggunakan setiap input samapi produk penerimaan marjinal dari input sama dengan biaya sumberdaya marjinal untuk menyewa input tersebut. Jika upah sebesar w dan sewa modal $\mathrm{r}$, maka laba maksimum akan dicapai ketika menggunakan tenaga kerja dan modal sampai :

$$
\mathrm{MRPl}=\mathrm{w} \quad \text { dan MRPk }=\mathrm{r}
$$

Atau dapat ditulis menjadi MP1 / MPK $=\mathrm{w} / \mathrm{r}$ atau $\mathrm{MP1} / \mathrm{w}=\mathrm{MPk} / \mathrm{r}$

Sedangkan Heady (1957) pengkombinasian input yang meminimumkan biaya kombinasi input adalah jika

$$
\text { MRTSxy }=\mathrm{Py} / \mathrm{Px}
$$

Jika MRTS tidak sama dengan ratio kebalikan harga input, produsen perlu melakukan usaha dengan menambah atau mengurangi salah satu input dengan mengurangi atau menambah input lainnya, sampai pada situasi MRTS sama dengan ratio harganya.

\section{Hasil Penelitian dan Pembahasan}

\subsection{Penggunaan Saprodi dan Produktivitas}

Dalam memproduksi cabai merah besar, petani produsen menggunakan berbagai sarana produksi, yaitu : lahan, benih, pupuk, obat obatan. Dari 56 responden luas garapan petani rata rata 0,28 ha, dengan produktivitas cabai $13.853 \mathrm{~kg} / \mathrm{ha}$. Sebahagian besar responden mempunyai luas garapan berkisar antara 20 are - 30 are. Pupuk yang digunakan petani adalah: Urea, ZA, KCl, TSP, dan NPK, dengan dosis masing masing per hektarnya 143,91kg. ; 369,19 kg. ; 228,48 kg. ; 212,73 kg. dan $329,90 \mathrm{~kg}$. Bagaimana pengaruh penggunaan pupuk terhadap produksi cabai merah, disajikan dalam tabel berikut. 
Tabel 1.

Pengaruh pupuk terhadap produksi cabai merah besar.

\begin{tabular}{clccl}
\hline No. & Variabel : & Rata rata (kg/ha) & $\begin{array}{c}\text { Produk Marjinal } \\
(\Delta \mathrm{Q} / \Delta \mathrm{Xi})\end{array}$ & Keterangan \\
\hline 1 & Produksi & 13,853 & - & - \\
2 & Urea & 143,91 & 1,463 & Sangat berarti \\
3 & ZA & 369,19 & 3,826 & Tidak berarti \\
4 & KCl & 228,48 & $-0,671$ & Tidak berarti \\
5 & TSP & 212,73 & 3,891 & Tidak berarti \\
6 & NPK & 329,90 & 12,092 & Sangat berarti \\
\hline
\end{tabular}

Dalam tabel 1 nampak bahwa, penggunaan pupuk telah sesuai dengan anjuran. Dari lima macam pupuk yang digunakan, hanya dua yang berpengaruh nyata yaitu pupuk urea dan NPK terhadap produksi, sedangkan $\mathrm{Za}, \mathrm{KCl}$ dan TSP tidak berpengaruh. Ini artinya ketiga pupuk ini penggunaannya telah maksimum pada luas garapannya. Pupuk urea dan NPK masih mempunyai peluang untuk ditambahkan agar $\mathrm{m}$ produksi meningkat. Tambahan $1 \mathrm{~kg}$ urea masih dapat meningkat produksi $1,463 \mathrm{~kg} / \mathrm{ha}$, dan tambahan $1 \mathrm{~kg}$ pupuk NPK akan dapat meningkatkan produksi $12,092 \mathrm{~kg} / \mathrm{ha}$.

\subsection{Marginal Rate of Technical Substitution (MRTS)}

Analisis MRTS ini menunjukkan nbagaimana hubungan antara input khususnya input pupuk yang dialokasikan oleh petani dalam usahatani cabainya, apakah bersubstitusi ataukah komplementer. Hasil analisis dari lima jenis pupuk yang digunakan disajikan dalam table berikut.

Tabel 2.

Hubungan antar jenis jenis pupuk dalam usahatani cabai merah

\begin{tabular}{clccc}
\hline No. & $\begin{array}{l}\text { Jenis pupuk } \\
\text { (Variabel Yi) }\end{array}$ & $\begin{array}{l}\text { Jenis pupuk } \\
(\text { Variabel Xi) }\end{array}$ & $\begin{array}{l}\text { MRTS } \\
(\Delta \mathrm{Yi} / \Delta \mathrm{Xi})\end{array}$ & Keterangan \\
\hline 1 & Urea : & ZA & 0,081 & Komplementer \\
& & KCl & 0,135 & Komplementer \\
& & TSP & 0,015 & Komplementer \\
& & NPK & $-0,058$ & substitusi \\
2 & ZA : & KCl & 0,349 & Komplementer \\
& & TSP & 0,380 & Komplementer \\
& & NPK & $-0,118$ & substitusi \\
3 & \multirow{2}{*}{ KCl : } & TSP & 0,708 & Komplementer \\
& & NPK & 0,096 & komplementer \\
4 & TSP : & NPK & 0,088 & komplementer \\
\hline
\end{tabular}

Keterangan : komlementer artinya jika Xi bertambah, Yi juga bertambah substitusi artinya jika Xi ditambahkan, Yi dikurangkan 
Secara umum petani cabai telah menggunakan pupuk berimbang, tetapi petani masih mempunyai kecenderungan untuk menggunakan urea berlebihan, nampak pada kombinasi penggunaan urea dan $\mathrm{Za}$ yang komplementer. Tetapi dalam kombinasi penggunaan pupuk urea dengan NPK mapun dalam kombinasi penggunaan ZA dengan dengan NPK telah bersifat substitusi (saling menggantikan antar kedua pupuk itu). Petani cabai berperilaku dalam melakukan pengkombinasian pupuk urea dengan NPK, jika pupuk NPK ditambahkan $1 \mathrm{~kg} / \mathrm{ha}$ nya, akan mengurangi penggunaan urea $0,058 \mathrm{~kg} / \mathrm{ha}$. Demikian pula terhadap penggunaan ZA, jika NPK dinaikan $1 \mathrm{~kg} / \mathrm{ha}$, petani akan menurunkan penggunaan ZA 0,118 kg/ha. Ini berarti $1 \mathrm{~kg}$ NPK dapat mengganti 0,118 kg ZA, dan dapat mengganti 0,058 kg urea. Pupuk NPK lebih mudah menggantikan ZA dari pada urea. Penggunaan pupuk yang bersifat komplementer adalah bila penggunaan salah satu jenis pupuk ditambahkan akan memerlukan tambahan juga pada jenis pupuk yang lainnya. Seperti dalam penggunaan urea kombinasi dengan $\mathrm{KCl}$. JIka Kcl ditambahkan akan memerlukan tambahan juga dalam penggunaan urea. Demikian pula pupuk yang lainnya.

\subsection{Pengaruh dalam Kombinasi Penggunaan Pupuk}

Pada usahatani yang menggunakan kombinasi berbagai jenis pupuk, tentu antar input akan saling berpengaruh dalam memproduksi komoditi. Komoditi yang dihasilkannya merupakan resultan dari kombinasi pupuk. Pengaruh antar pupuk yang dikombinasikan penggunaannya dalam usahatani cabai merah besar, dianalisis dari elastisitas hubungan factor pupuk. Hasil analisis disajikan dalam tebel dibawah ini.

Tabel 3.

Pengaruh antar pupuk dalam Usahatani Cabai Merah Besar

\begin{tabular}{cccccc}
\hline No. & $\begin{array}{c}\text { Variabel } \\
\text { Yi }\end{array}$ & $\begin{array}{c}\text { Variabel } \\
\mathrm{Xi}\end{array}$ & $\begin{array}{c}\text { MRTS } \\
(\Delta \mathrm{Yi} / \Delta \mathrm{Xi})\end{array}$ & $\begin{array}{c}\text { Rata rata } \\
\text { Yi/Xi }\end{array}$ & $\begin{array}{c}\text { Pengaruh Xi } \\
\text { thpYi }(\%)\end{array}$ \\
\hline 1 & Urea : & $\mathrm{ZA}$ & 0,081 & 2,565 & 20,78 \\
& & $\mathrm{KCl}$ & 0,135 & 1,588 & 21,43 \\
& & $\mathrm{TSP}$ & 0,015 & 1,478 & 2,22 \\
& & $\mathrm{NPK}$ & $-0,058$ & 2,292 & $-13,30$ \\
2 & $\mathrm{ZA}:$ & $\mathrm{KCl}$ & 0,349 & 0,618 & 21,60 \\
& & $\mathrm{TSP}$ & 0,380 & 0,576 & 21,90 \\
& & $\mathrm{NPK}$ & $-0,118$ & 0,650 & $-10,54$ \\
3 & $\mathrm{KCl}:$ & $\mathrm{TSP}$ & 0,708 & 0,931 & 65,59 \\
& & $\mathrm{NPK}$ & 0,096 & 1,006 & 9,66 \\
4 & $\mathrm{TSP}:$ & $\mathrm{NPK}$ & 0,088 & 1,550 & 13,65 \\
\hline
\end{tabular}

Hasil analisis nampak bahwa, ada sebagian yang mempunyai pengaruh positif, dan ada dua pupuk yang berpengaruh negative yaitu NPK terhadap urea dan terhadap ZA. Berpengaruh positif artinya jika pupuk Xi ditambahkan atau dikurangkan maka pupuk Yi akan minta untuk ditambahkan ataupun dikurangkan. Misalnya pengaruh ZA terhadap urea. Jika ZA pengguna annya dinaikkan $1 \%$ maka 
urea harus ditambahkan 20,78\%. Berbeda dengan pengaruh NPK terhadap urea, jika penggunaan NPK ditambahkan $1 \%$ maka urea mesti penggunaanya dikurangkan $13,30 \%$. Pupuk NPK bersubstitusi tidak sempurna dengan ZA maupun dengan urea, hanya $11 \%$ dengan ZA dan hanya $13 \%$ dengan urea. Pupuk yang mempunyai pengaruh paling besar adalah pupuk TSP terhadap pupuk KCl. Sedangkan yang mempunyai pengaruh paling kecil adalah pupuk TSP terhadap pupuk urea. Secara umum kombinasi penggunaan pupuk saling berpengaruh antara $10 \%-22 \%$.

\subsection{Kombinasi Pupuk Optimal}

Setiap usahatani diasumsikan menggunakan sarana produksi khususnya pupuk sedemikian rupa agar biaya untuk pupuk serendah mungkin. Sementara laba usahatani diharapkan maksimal, tidak terkecuali usahatani apapun. Penggunaan pupuk yang optimal agar biaya pupuk menjadi minimal jika terpenuhi persyaratan MRTS sama dengan rasio kebalikan harga pupuk (Heady, 1957). Hasil analisis optimalisasi kombinasi penggunaan pupuk pada usahatani cabai merah besar, tertera dalam tabel berikut.

Tabel. 4.

Optimalisasi Kombinasai Penggunaan Pupuk pada Usahatani Cabai Merah Besar.

\begin{tabular}{|c|c|c|c|c|c|}
\hline No. & $\begin{array}{l}\text { Variabel } \\
\mathrm{Yi}\end{array}$ & $\begin{array}{l}\text { Variabel } \\
\mathrm{Xi}\end{array}$ & $\begin{array}{l}\text { MRTS } \\
(\Delta Y \mathrm{Y} / \Delta \mathrm{Xi})\end{array}$ & $\begin{array}{l}\text { Rasio harga } \\
\mathrm{Xi} / \mathrm{Yi}\end{array}$ & Keterangan \\
\hline \multirow[t]{4}{*}{1} & Urea : & ZA & 0,081 & 0,946 & belum optimal \\
\hline & & $\mathrm{KCl}$ & 0,135 & 0,874 & \\
\hline & & TSP & 0,015 & 0,932 & \\
\hline & & NPK & $-0,058$ & 4,137 & \\
\hline \multirow[t]{3}{*}{2} & ZA : & $\mathrm{KCl}$ & 0,349 & 0,924 & belum optimal \\
\hline & & TSP & 0,380 & 0,985 & \\
\hline & & NPK & $-0,118$ & 4,373 & \\
\hline \multirow[t]{2}{*}{3} & $\mathrm{KCl}:$ & TSP & 0,708 & 1,066 & belum optimal \\
\hline & & NPK & 0,096 & 1,473 & \\
\hline 4 & TSP : & NPK & 0,088 & 4,438 & belum optimal \\
\hline
\end{tabular}

Ternyata hasil analisis menunjukkan bahwa usahatani cabai merah besar yang menggunakan kombinasi empat jenis pupukm : urea, ZA, KCl,TSP dan NPK yang diusahakan oleh petani kondisi biaya minimal belum tercapai. Petani masih harus meningkatkan keterampilannya agar kombinasi penggunaan input agar menghabiskan biaya yang sekecil mungkin, terutama pada kombinasi penggunaan pupuk NPK dengan ZA dan urea. 


\section{Simpulan dan Saran}

\subsection{Simpulan}

Berapa simpulan yang dapat diambil dari uraian diatas adalah :

1. Kombinasi pupuk (urea, ZA, KCl,TSP, NPK) yang digunakan oleh petani cabai merah besar, hanya pupuk NPK yang bersubstitusi dengan pupuk ZA dan pupuk urea. Sedangkan pupuk yang lainnya bersifat komlementer.

2. MRTS urea dengan NPK sebesar - 0,058, dan MTRS ZA dengan NPK sebesar $-0,118$.

3. Pupuk NPK bersubstitusi tidak sempurna terhadap pupuk ZA maupun terhadap pupuk urea. Daya substitusinya hanya $11 \%$ terhadap ZA dan $13 \%$ terhadap urea.

4. Dari kombinasi penggunaan pupuk pada usahatani cabai merah besar, tidak satupun kombinasinya optimal.

\subsection{Saran}

Hal yang dapat disarankan dari hasil penelitian ini adalah disarankan kepada petani agar meningkatkan keterampilannya dalam penggunaan kombinasi berbagai jenis pupuk dalam usahatani cabai, agar biaya dapat ditekan sekecil mungkin, sehingga laba usahatani yang diperoleh menjadi maksimal.

\section{Daftra Pustaka}

Arsyad, Lincolin (1996). Ekonomi Manajerial. Ekonomi Mikro Terapan Untuk Manajemen Bisnis. BPFE. Yogyakarta.

Heady, O. Earl (1957). Economics of Agricultural Production and Resource Use. Prentice - Hill, Inc. Englewood Cliff. N.J.

Salvatore, Dominick (2002). Managerial Economics dalam Perekonomian Global. Edisi Kempat. Jilid 1. Alih BahasaIr. M.Th. Anitawati,MSc.PT Penerbit Erlangga. Jakarta. 